\title{
Looking Back and Looking Ahead: Adult Age Differences in Consistency of Diachronous Ratings of Subjective Well-Being
}

\author{
Ursula M. Staudinger \\ Dresden University
}

\author{
Susan Bluck \\ University of Florida
}

\author{
P. Yorck Herzberg \\ Dresden University
}

\begin{abstract}
The goal of this study is to investigate the consistency of diachronous ratings of subjective well-being (SWB). A heterogeneous sample (25-74-year-olds; $N=3,596)$ provided ratings of their present SWB, reconstructed their SWB of 10 years ago, and anticipated their SWB 10 years from now. Developmental tasks and self-evaluative principles were used to predict age differences in diachronous consistency. As predicted, in young adulthood, past SWB was rated lower and future SWB higher than present SWB. In contrast, in later adulthood, the past was rated higher and the future lower than present SWB. Analyses of rank-order consistency demonstrated that in later adulthood both future and past SWB were more strongly related to present SWB than in young adulthood. Results show how models of self-evaluation play out at different points in the life span.
\end{abstract}

\section{Diachronicity of Self-Evaluations}

Though rooted in the present, human beings have the capacity to extend the self (Neisser, 1988) through memory of their past and contemplation of their future. Lewin (1926) argued that human functioning could be understood in terms of a person's "life space," encompassing both a physical and a temporal dimension. This notion that human life is constituted by synchronous (i.e., coexistent) as well as diachronous (i.e., spread across time) processes also has a long tradition in philosophy (e.g., Heidegger, 1927/1979; Jaspers, 1932).

Exploring the objective and subjective facets of the diachronous nature of life is central to lifespan theory (e.g., Baltes, Reese, \& Lipsitt, 1980; Bühler, 1933; Ryff \& Baltes, 1976; Ryff \& Heincke, 1983; Staudinger, 1999). In this article, we are less interested in objective or chronological time, as examined in longitudinal work. Rather, we focus on subjective or psychological time: evaluations of subjective well-being (SWB) in the past and the future and how

Ursula M. Staudinger and P. Yorck Herzberg, Department of Psychology, Area of Lifespan Development, Dresden University; Susan Bluck, Department of Liberal Arts and Sciences, University of Florida.

This research was supported by the John D. and Catherine T. MacArthur Foundation Research Network on Successful Midlife Development (MIDMAC) and the Max Planck Institute for Human Development, Center for Lifespan Development. The data are from the Midlife in the United States Survey. We thank our colleagues in the MacArthur Research Network on Successful Midlife Development and at the Max Planck Institute for their cooperation and many valuable suggestions. We also thank Monisha Pasupathi for her helpful comments on a draft of the article.

Correspondence concerning this article should be addressed to Ursula M. Staudinger, Department of Psychology, Dresden University, 01062 Dresden, Germany. E-mail: staudinger@psychologie.tu-dresden.de consistent those diachronous ratings (past, future) are with evaluations of present SWB. This notion of psychological time has been studied also by social psychologists in investigations concerning, for instance, self-evaluative (e.g., Schwarz \& Strack, 1999; Taylor, Neter, \& Wayment, 1995) and comparison processes (e.g., Albert, 1977; Suls \& Mullen, 1982; Wilson \& Ross, 2001), or possible selves (e.g., Markus \& Nurius, 1986). This research suggests that we construct our selves with regard to the past, and the present, as well as the future (e.g., Hooker, 1992), and that we use diachronous referents as often as social referents in our comparison processes (e.g., Wilson \& Ross, 2000).

In this article, we build on and interrelate results from these different areas of the study of diachronicity. We conclude from our reading of the literature that research on diachronous selfevaluations, to date, is characterized by three emphases. First, most studies have been conducted in the field of self and personality characteristics (e.g., Fleeson \& Baltes, 1998; Fleeson \& Heckhausen, 1997; Ryff, 1991; Ryff \& Heincke, 1983; Wilson \& Ross, 2001). ${ }^{1}$ Second, there are fewer studies that combine all three types of diachronous rating, that is, past, present, and future evaluations (for exception, see, e.g., Ross \& Buehler, 2001; Ryff, 1991). Mostly, there is emphasis on comparing either past or future evaluations with present self-evaluations (e.g., Conway \& Ross, 1984; Cross \& Markus, 1991; Ross, 1989; Wilson \& Ross, 2001; Woodruff \& Birren, 1972). And third, with a few exceptions (e.g., Fleeson \& Baltes, 1998), consistency among diachronous evalua-

\footnotetext{
${ }^{1}$ We acknowledge that Carol Ryff (e.g., 1991) investigates psychological well-being. To not confuse hedonic and growth-oriented well-being (e.g., Ryan \& Deci, 2001), however, we have chosen for simplicity reasons to categorize her study under self- and personality characteristics rather than subjective well-being.
} 
tions is investigated by comparing solely mean levels without inspecting rank orders. Comparison of mean levels, though, represents only half of the picture. For example, on average, young and middle-aged participants report positive differences between their past and their present (i.e., success stories; e.g., Wilson \& Ross, 2001), but this does not exclude the possibility that some individuals do not report differences at all and that others may actually communicate decreases. Those individual differences are only captured when also comparing rank orders. The present study aims to combine those emphases by focusing on adult age differences in both mean-level and rank-order consistency of diachronous ratings (past, present, and future) of subjective well-being.

\section{Diachronous Ratings of Subjective Well-Being}

Our interest in diachronous self-evaluations focuses on ratings of SWB. Prior research has demonstrated that SWB is multifaceted. It includes positive and negative affect, and life satisfaction, and it comprises both domain-general and domain-specific evaluations (e.g., Diener, Suh, Lucas, \& Smith, 1999). Elaborate theories have been developed and tested about the judgment processes underlying evaluations of one's present life (e.g., Schwarz \& Strack, 1999). Goal selection, level of aspiration, social and temporal comparison, and mood states, for instance, have received considerable attention when predicting present ratings of SWB across the adult life span (e.g., Brandtstädter \& Greve, 1994; Kahneman, Diener, \& Schwarz, 1999; Staudinger, 2000).

We know of only one study, however, that has investigated the mean-level consistency of diachronous evaluations of SWB (i.e., past, present, and future). In their classic study on the relativity of happiness, Brickman, Coates, and Janoff-Bulman (1978) asked lottery winners, accident victims, and controls about their happiness before winning or being involved in an accident both at the present stage of their life and in a couple of years. Ratings of future SWB were significantly higher than present ratings for all three groups. Ratings of present and of past happiness, though, demonstrated group differences such that the accident victims rated past happiness higher than the present, whereas the other two groups demonstrated the reversed pattern. Brickman et al. (1978) called the former a "nostalgia effect" (p. 924). Their results demonstrate that depending on life contexts, evaluations of subjective wellbeing in the past can be higher, the same, or lower than evaluations of the present. Especially, present life circumstances that involve many losses as compared to the past, seem to be conducive to the nostalgia effect. Conversely, evaluations of future SWB seem to be-irrespective of life circumstances-higher than evaluations of present SWB, at least in a sample covering young and middle adulthood.

\section{Diachronicity Across the Life Span}

The following three assumptions, derived from temporal comparison theory, social-cognitive theorizing, and lifespan theory, provide the basic framework for the study. The first is that temporal comparisons involve perceiving change such that the sense of a coherent self is maintained over time (e.g., Erikson, 1959; James, 1890/1948). According to lifespan theory, however, the self is confronting different developmental tasks, or challenges to coherence, at different ages. Thus, coherence denotes a growing self in young adulthood, whereas in middle adulthood and old age a coherent self increasingly refers to maintaining or repairing the self in the face of losses (Baltes, Lindenberger, \& Staudinger, 1998) and to integration of the self in the face of death (Erikson, 1959).

The second assumption is that diachronous self-evaluations are guided by any combination of the following motives: self-assessment, self-enhancement, self-verification, and selfimprovement (Taylor et al., 1995). Taylor et al. (1995) found that evaluations of the past primarily serve purposes of selfenhancement and self-assessment and that evaluations of the future predominantly support the quest for self-improvement. For selfenhancement and self-improvement to be adaptive, they should both follow the rule of the optimal margin of illusion to be functional (e.g., Baumeister, 1989; Staudinger \& Pasupathi, 2000).

Finally, the third assumption is based on Schwarz and Strack's (1991) judgment theory of well-being. They have repeatedly found that the similarity of diachronous evaluations is smaller if the ratings belong to different subjective categories of time (i.e., contrast vs. assimilation effect). The likelihood that the past and the future, in an ontogenetic sense, are considered as belonging to a different time category than the present is higher in young than in old adulthood. Why is that? One reason is respective developmental tasks, that is, change and growth for young adulthood (i.e., difference), and maintenance and integration across midlife and into later adulthood (i.e., sameness; e.g., Baltes et al., 1998). We also know that older adults' time experience is different from that of younger adults. It is characterized by experiencing time as passing faster (e.g., Levin \& Zakay, 1989; Wallach \& Green, 1961) and by experiencing what Nuttin (1985) calls an "open present" rather than being aware of the present and the future as separate categories. In the following, we develop the hypotheses guiding the present study by referring to these basic assumptions.

\section{Overall Consistency of Diachronous Subjective Well-Being}

Present well-being relies on the current life situation but also on appraisals of the past and on expectations for future well-being (e.g., Karniol \& Ross, 1996; Lewin, 1926; Markus \& Wurf, 1987). Individuals are able to make predictions about what will happen in the future by comparing present events with previously gained knowledge and by using imagination (Lockhart, 1989; Smith, 1996). In contrast to assessing the past, evaluating the future is not constrained by actual events that have taken place. Furthermore, projections into the future are characterized by a self-deceptive optimistic bias guided by the motive of self-improvement (e.g., Robinson \& Ryff, 1999; Ross \& Newby-Clark, 1998; Taylor \& Brown, 1988), whereas evaluations of past well-being pursue the need for self-enhancement and usually result in a derogation of the past as compared to the present (e.g., Wilson \& Ross, 2001).

In sum, we predict that overall mean-level consistency of present and future SWB should be smaller than of past and present ratings. In fact, it may be possible, as the study by Brickman et al. (1978) has demonstrated, that in a sample covering very different life circumstances, as is the case in an adult lifespan sample, no overall mean differences between ratings of past and present SWB are observed because enhancement and nostalgia effects offset each other. As much as mean levels of future and present SWB are 
expected to differ, rank orders are predicted to stay the same. We assume that projections into the future are often guided by an optimistic bias, whereas evaluations of the past are to some degree constrained by actual events and therefore idiosyncratic influences are more likely that may result in rank-order changes. Thus, the correlation between future and present ratings of SWB is expected to be stronger than that between ratings of past and present SWB.

\section{Age Differences in Consistency of Past and Present Subjective Well-Being}

The past and the present certainly have a reciprocal relationship (Bluck \& Levine, 1998): Evaluations of the personal past may be influenced by one's present views (Karney \& Coombs, 2000; Levine, 1997), and the past may also affect the present (e.g., Conway \& Ross, 1984). On the basis of the three assumptions laid out above, we derive the following hypotheses about potential mean-level age differences between evaluations of past and present SWB. Young adulthood is primarily characterized by the developmental task of growth or positive change (Baltes et al., 1998) as well as by perceived growth trajectories (e.g., Heckhausen, Dixon, \& Baltes, 1989). In addition, self-evaluations of the past primarily pursue the self-enhancement and the selfassessment motive (Taylor et al., 1995), and younger adults are more likely to perceive the past and the present as not belonging to the same time category. Taken together this suggests that in young adulthood, evaluations of SWB in the past will, on average, be lower than evaluations of present well-being.

In midlife and increasingly in old age, the main developmental task is maintenance, repair, and loss management, but the prime motives guiding self-evaluations are still, as in young adulthood, self-enhancement and self-assessment. Self-enhancement and selfassessment, however, have different consequences if the prime task is maintenance but the perceived developmental trajectory is decline (e.g., Baltes \& Mayer, 1999; Heckhausen et al., 1989). The past again is derogated (see Wilson \& Ross, 2001), but criticizing the past in the face of a decline trajectory implies that rather than rating the past higher than the present, it is more and more rated about the same, that is, less and less mean differences between evaluations of past and present SWB are expected in midlife and old age.

Expectations about rank-order consistency of past and present SWB in later adulthood are derived from the proposition that the past and the present are more likely considered as part of the same subjective time category and that the maintenance task makes it less likely that major changes introduce shifts in rank orders: Increasingly higher positive interrelations between past and present ratings of SWB are expected starting in midlife than in young adulthood. The interrelation between past and present SWB in young adulthood will be substantial and in the positive. It will be smaller, however, than in middle and later adulthood, as young adults are more likely to consider the past a different time category than the present and the development task of positive change makes changes in rank order more likely than later in adulthood.

\section{Age Differences in Consistency of Future and Present Subjective Well-Being}

We think about the future quite often in relation to our goals (Karniol \& Ross, 1996). Lifespan theory predicts, and consistent evidence has accrued, that prevailing types of goals vary with age. We assumed above that in young adulthood growth goals reign supreme whereas later in adulthood goals of maintenance, repair, and loss management come to the foreground (Baltes et al., 1998). In combination with the other two propositions, we expect that the self-improvement motive will lead (a) to an exaggeration of the expected growth in young adulthood, (b) to expecting some growth rather than maintenance in middle adulthood, and (c) to an understatement of expected losses in later adulthood (e.g., Staudinger \& Bluck, 2001). Thus, in young adulthood we expect sizeable positive mean differences between ratings of present and future wellbeing. We predict to find smaller positive differences between ratings of future and present SWB in midlife, and no mean differences in old age. This expectation is consistent with findings from earlier research on diachronous ratings of personality attributes (e.g., Fleeson \& Heckhausen, 1997; Ryff, 1991).

With regard to rank-order consistency of present and future SWB, we predict that the relation is weaker in young adulthood, grows stronger in midlife, and is largest in later adulthood because projections of change rather than stability-introducing more idiosyncrasy_ can be expected to influence evaluations of the future in young adulthood.

\section{Method}

\section{Sample}

The sample consisted of 3,596 community-dwelling adult participants from the Midlife in the United States Survey (MIDUS), conducted by the John D. and Catherine T. MacArthur Foundation Research Network on Successful Midlife Development. This national probability sample was recruited by using random digit dialing. Respondents were interviewed for 20-30 min by telephone (70\% response rate) and also completed a selfadministered questionnaire that they received in the mail $(87 \%$ response rate). Only questionnaire data were used in the current study. The sample ranges in age from 25 to 74 years $(M=46.9, S D=13.2)$, and is made up of approximately equal numbers of men (56\%) and women $(44 \%)$. The sample is primarily Caucasian (90\%), but it also includes some African Americans (8\%), Asian Americans (1\%), and Native Americans (1\%). Although some participants had not finished high school $(9 \%)$, most had finished high school $(29 \%)$, had some college $(29 \%)$, or had completed a bachelor's degree or higher $(33 \%)$. In sum, this is a heterogeneous sample though it tends to overrepresent Caucasians and well-educated individuals.

For the mean-level analyses, the continuous age distribution is split into three age groups: young adulthood, ranging from 25 to $40(N=1,297$, $M=32.8, S D=4.5)$; middle adulthood, ranging from 41 to 54 $(N=1,182, M=47.3, S D=3.9) ;$ and old age ranging from 55 to 74 $(N=1,117, M=63.1, S D=5.7)$.

\section{Measures and Procedure}

Because the present research is part of the larger MIDUS survey, measures were included in that data collection that are not used in the current analyses. Only the measures of interest for the current study are described here. More information concerning these measures and regarding the MIDUS survey is detailed elsewhere (MIDMAC, 1998).

Diachronous measures of SWB. Subjective well-being can be assessed in a domain-general and a domain-specific manner (Diener et al., 1999). Prior research that used these different assessment formats has demonstrated that domain-specific ratings are formed following a bottom-up judgment process, whereas domain-general overall SWB ratings are formed according to top-down mechanisms (Campbell, Converse, \& Rod- 
gers, 1976; Headey \& Wearing, 1989). Actual life circumstances arerelatively speaking-more strongly reflected in domain-specific than in general SWB ratings. Because of this study's focus on age differences in diachronous consistency of SWB ratings in relation to changing life contexts, we included an SWB scale consisting of six life-domain ratings rather than an overall SWB scale. For later analyses, those six life-domain ratings were averaged within each temporal instruction (see below).

Participants provided evaluations of SWB in six life domains in the past (10 years ago), the present, and the anticipated future (10 years from now). The domains included partnership, sexuality, finances, work, health, and welfare of others. Ratings were made on 11-point scales based on Cantril's (1965) self-anchoring scale. For example, in making their evaluation of the present, past, and future in the domain of health, participants responded to the questions,

(1) Using a scale from 0 to 10 where 0 means 'the worst possible health' and 10 means 'the best possible health,' how would you rate your health these days? (2) Looking back ten years ago, how would you rate your health at that time using the same scale? and (3) Looking ahead ten years into the future, what do you expect your health will be like at that time?

Similar to Ryff (1991), we used a fixed time difference, in our case 10 years ahead or back in time, to obtain diachronous ratings. This implied that the age groups were not referring to the same periods of the life span when making their judgments. These instructions emphasize the focus of the present study on the diachronicity of SWB, that is, subjective conceptions of temporal extension rather than subjective conceptions of particular developmental periods (e.g., for the latter focus see Fleeson \& Baltes, 1998; Fleeson \& Heckhausen, 1997; Ryff \& Heincke, 1983).

As in other studies that used temporal instructions, questions were always answered in the same sequence: present, past, and future. Prior research that used temporal instructions has demonstrated that participants find it difficult to provide diachronous ratings without first evaluating their present status (e.g., Fleeson \& Baltes, 1998; Fleeson \& Heckhausen, 1997; Ryff, 1991). Systematically varying the order of evaluation, however, does not yield significant order effects (Wilson \& Ross, 2001).

Even though the domain ratings were not assessed in sequence, but at several different points in a longer questionnaire, the SWB scales showed satisfactory internal consistency for ratings of past SWB (Cronbach's $\alpha=$ .64 ), present SWB (Cronbach's $\alpha=.64$ ), and future SWB (Cronbach's $\alpha=.72$ ). However, to further validate use of SWB scores averaged across domains, additional analyses were performed.

Testing the robustness of a one-factor solution: Equivalence of factor structure across age and type of diachronous rating. Averaging wellbeing ratings across domains was also supported when using confirmatory factor analysis (CFA) on the present ratings of SWB: A one-factor solution proved superior to a two-factor solution that had been identified in an exploratory factor analysis. (The first factor comprised the domains health, work, finances, and welfare of others, and the second factor comprised sexuality and partnership.) The fit of the one-factor model was $\chi^{2}(9$, $N=3,596)=106.79, p<.001$. Given our large sample size, we followed the recommendation of $\mathrm{Hu}$ and Bentler (1995) and used additional measures of fit: the root-mean-square error of approximation $($ RMSEA $)=.051$ (95\% confidence interval [CI]: .042-.059), the comparative fit index $(\mathrm{CFI})=.998$, normed fit index $(\mathrm{NFI})=.998$, and the Tucker-Lewis index $($ TLI $)=.995$ (Tucker \& Lewis, 1973) all indicated a good model fit. The two-factor model showed fit indices that are quite similar: $\chi^{2}(8$, $N=3,596)=80.23, p<.001$, RMSEA $=.046$ (95\% CI: .037-.056), $\mathrm{CFI}=.999, \mathrm{NFI}=.998$, and TLI $=.996$. Testing the differences between the models, however, revealed a significant improvement in model fit for chi-square $(\Delta=26.563, d f=1, p<.001)$, and marginal differences in indices for large samples (CFI: $\Delta<.001$; TLI: $\Delta<.001$ ). Following the principle of parsimony, we assumed the one-factor model as the most appropriate solution.
As the central aim of this article is to analyze age-related differences in consistency of diachronous ratings of SWB, we also wanted to examine whether the one-factor model held up across the age range covered by the present sample. Therefore, again using present ratings of SWB, we compared the equivalence of the measurement structure across age groups by means of a multigroup CFA. The test of measurement invariance yielded a good fit for the one-factor model for each of the three age groups: $\chi^{2}(24$, $N=3,596)=82.14, p<.001$, RMSEA $=.026$ (95\% CI: .020-.032), $\mathrm{CFI}=.999, \mathrm{NFI}=.998$ and $\mathrm{TLI}=.997$.

Finally, when comparing SWB ratings averaged across domains by past, present, and future ratings, we needed to establish the equivalence of the factor structure across types of diachronous rating. To do so, we compared the equivalence of the measurement structure across diachronous ratings by means of a multigroup CFA framework; that is, does the same factor structure hold up for present, future, and past ratings of SWB? The test of measurement invariance again yielded a good fit for the one-factor model: $\chi^{2}(24, N=3,596)=171.50, p<.001$, RMSEA $=.031(95 \% \mathrm{CI}:$ $.027-.035), \mathrm{CFI}=.973, \mathrm{NFI}=.969$, and TLI $=.951$. All CFAs were computed using the maximum-likelihood estimation procedure of AMOS (Arbuckle, 1999).

In sum, these analyses demonstrate that the one-factor structure is tenable across age and diachronous ratings. Thus, in all further analyses we use present, past, and future SWB scores averaged across the six domains. For reasons of psychometric quality, single-item domain ratings will only be used for illustrative purposes.

Convergent validity of present SWB: Other indicators of SWB. A second methodological concern was to demonstrate the convergent validity of our measure of present SWB. To explore the convergent validity of ratings of present SWB with extant indicators of subjective well-being, the correlations between present SWB and both affect and life satisfaction were computed (see Table 1). Affect was measured using 5-point scales $(1=$ none of the time to $5=$ all of the time $)$. Participants indicated the extent to which they had felt six negative (e.g., nervous, sad) and six positive (e.g., cheerful, satisfied) states in the last 30 days. An index of affect was created by reverse coding negative affect and then taking a mean across the 12 items (higher scores indicate greater positivity). The index showed a high interitem reliability (Cronbach's $\alpha=.92$ ). Life satisfaction (i.e., How satisfying is your life overall these days?) was measured as a single item using a 0 (worst possible life overall) to 10 (best possible life overall) scale.

Both affect and life satisfaction demonstrated substantial positive relations ( $r=.52$ and $r=.66)$ with our present ratings of SWB. These correlations suggest that our assessment of present SWB shares a substantial part of its variability with standard measures of SWB; thus, it indeed represents a measure of subjective well-being. The correlations do not reflect perfect overlap, which is certainly partially due to measurement error but is also in line-as argued above - with prior findings about the association between domain-specific and global SWB ratings (Diener, 1994).

Discriminant validity of diachronous SWB ratings: The Big Five and Agency. We wanted to make sure that diachronous ratings of SWB are not identical with various characteristics of dispositional personality such as neuroticism or conscientiousness (e.g., Costa \& McCrae, 1984). To test that assumption, we used an adjective measure of the five-factor model of personality using 4-point scales ("Indicate how well each adjective describes you, from 'a lot' to 'not at all'"; Trapnell \& Wiggins, 1990). Reliabilities (Cronbach's alpha) of the Big Five were good (Neuroticism, $\alpha=.69$; Extraversion, $\alpha=.85$; Openness, $\alpha=.89$; Agreeableness, $\alpha=$ .89; Conscientiousness, $\alpha=.74)$. Zero-order relations among the Big Five and the present or future ratings of SWB were-given the large sample size - significant but not very high (see Table 1). Relations with the past ratings were somewhat lower. As all five characteristics demonstrated significant relations, we included all five dimensions as control variables in the main analyses. 
Table 1

Correlations and Descriptives of Diachronous Ratings of Subjective Well-Being (SWB) and Other Study Variables

\begin{tabular}{|c|c|c|c|c|c|}
\hline \multirow[b]{2}{*}{ Study variables } & \multicolumn{3}{|c|}{ SWB ratings } & \multirow[b]{2}{*}{$M$} & \multirow[b]{2}{*}{$S D$} \\
\hline & Past & Present & Future & & \\
\hline Evaluation of present ${ }^{b}$ & $.36(.56)^{\mathrm{a}}$ & - & $.65(.96)^{\mathrm{a}}$ & 6.70 & 1.44 \\
\hline Evaluation of past ${ }^{\mathrm{b}}$ & - & - & $.09(.13)^{\mathrm{a}}$ & 6.71 & 1.46 \\
\hline Evaluation of future ${ }^{b}$ & - & - & - & 7.19 & 1.62 \\
\hline Age (in years) & .35 & .04 & -.42 & 46.98 & 13.24 \\
\hline Affect ${ }^{c}$ & .22 & .52 & .33 & 3.90 & .62 \\
\hline Life Satisfaction ${ }^{\mathrm{b}}$ & .29 & .66 & .40 & 7.63 & 1.67 \\
\hline Neuroticism $^{\mathrm{d}}$ & -.17 & -.31 & -.18 & 2.25 & .66 \\
\hline Extraversion $^{\mathrm{d}}$ & .15 & .27 & .26 & 3.20 & .56 \\
\hline Openness $^{\mathrm{d}}$ & .06 & .19 & .27 & 3.05 & .52 \\
\hline Conscientiousness $^{\mathrm{d}}$ & .19 & .28 & .21 & 3.41 & .45 \\
\hline Agreeableness $^{\mathrm{d}}$ & .18 & .17 & .14 & 3.48 & .50 \\
\hline Agency $^{\mathrm{d}}$ & .10 & .18 & .19 & 2.73 & .66 \\
\hline
\end{tabular}

Note. All reported correlations are significant at $p<.01 . N=3,596$.

${ }^{\mathrm{a}}$ Values in parentheses refer to disattenuated correlations. ${ }^{\mathrm{b}}$ Maximum $=10 .{ }^{\mathrm{c}}$ Maximum $=5$. ${ }^{\mathrm{d}}$ Maximum $=4$.

In addition to the Big Five, it seemed useful to determine discriminant validity also vis-à-vis the personality dimension Agency as, for instance, evaluations of the future may depend on this personality characteristic. We assessed Agency by using 4-point scales ("Indicate how well each adjective describes you, from 'a lot' to 'not at all'"; Trapnell \& Wiggins, 1990). Across five items (e.g., forceful, assertive), the scale reliability with Cronbach's $\alpha=.80$ was good. As Agency demonstrated significant relation with the three diachronous ratings, we included this dimension also as a control variable in the main analyses. Table 1 provides the means and standard deviations and lists the zero-order correlations for all study variables.

\section{Results}

The results are organized in three sections. First, we examined overall mean-level and rank-order consistencies of diachronous ratings of SWB. Second, age differences in mean-levels of diachronous ratings of SWB were tested. Finally, we investigated age differences in the rank-order consistency between present SWB and past or future SWB.

\section{Overall Mean-Level and Rank-Order Consistencies}

Diachronous SWB ratings were analyzed in a 3 (type of diachronous rating) $\times 3$ (age group) repeated-measures analysis of variance (ANOVA), in which age group was the between-subjects factor and type of diachronous rating the within-subject factor. ${ }^{2}$ The within-subjects effect of diachronous rating was significant, $F(2,7186)=193.86, p<.001$, but rather small, $\eta^{2}=.05$. Age group showed no significant main effect, $F(2,3593)=2.11, p>$ $.05, \eta^{2}=.001$.

Follow-up analyses further examined the overall differences in mean levels of diachronous ratings. For that purpose two orthogonal contrasts, one comparing past and present ratings and the other comparing present and future ratings, were computed. The difference between past and present evaluations was not significant, $F(1,3593)=1.27, p>.05$, but as expected evaluations of future SWB were found to be significantly higher than those of the present, $F(1,3593)=580.36, p<.001, \eta^{2}=.14($ see Table 1 for $M \mathrm{~s}$ and $S D \mathrm{~s})$.

As expected with regard to overall rank-order consistency and as shown in Table 1, the correlation between evaluations of past and present SWB was smaller than that between future and present ratings (Fisher's $Z=23.88 ; p<.001$ ). This held true as well for disattenuated correlations (Fisher's $Z=78.71 ; p<.001$ ).

\section{Age Differences in Mean-Level Consistency of Diachronous Ratings of SWB}

Further, the interaction between age and type of diachronous ratings was significant, $F(4,7186)=500.90, p<.001$, and it showed a substantial effect size, $\eta^{2}=.22$. As a follow-up, repeated-measures analyses with type of diachronous rating as within-subject factor were computed for each age group. In the top panel of Figure 1, mean-level differences are plotted by type of diachronous rating. The bottom panel of Figure 1 depicts mean differences by age group and thus pictures trajectories of subjective change.

For young adults, statistically significant differences emerged between past and present ratings, $F(1,1296)=100.11, p<.001$, $\eta^{2}=.07$. In line with our hypotheses, higher ratings were given for present SWB (see also Figure 1). Also consistent with our expectations, future evaluations of SWB were much higher compared with present ratings of SWB, $F(1,1296)=1596.00, p<$ $.001, \eta^{2}=.55$ (see Figure 1 ).

For middle-aged adults, present SWB ratings were not distinct from past ratings, $F(1,1181)=0.15, n s$. Future ratings, however, were found to be higher than present and past ratings of SWB, $F(1$, $1181)=280.07, p<.001, \eta^{2}=.19$ (see Figure 1). In the group of older adults, past and future ratings differed from the evaluation

\footnotetext{
${ }^{2}$ We computed an analysis of covariance to control for the six personality attributes. The pattern of results remained basically unchanged throughout the analysis.
} 

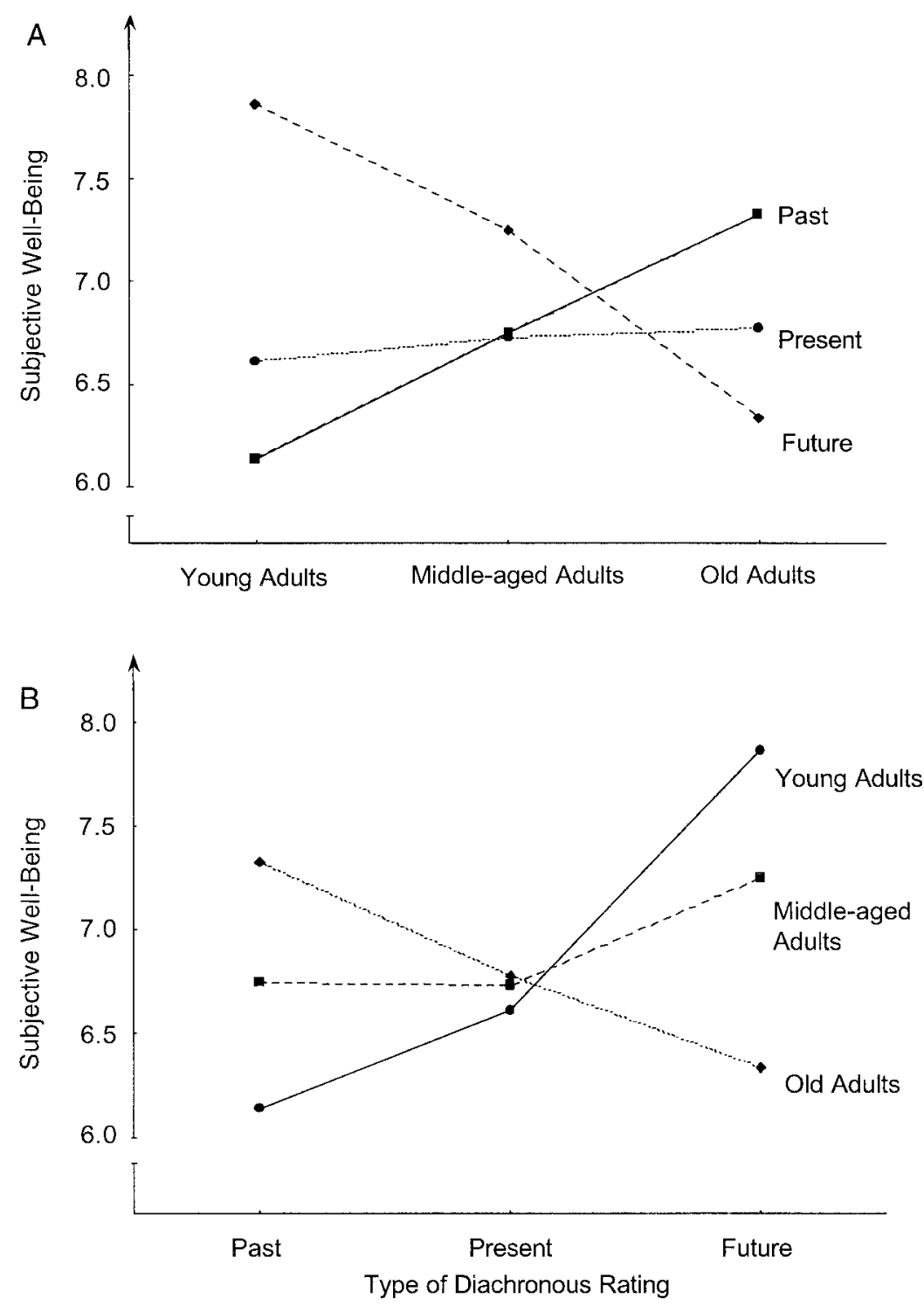

Figure 1. Mean differences among present, past, and future evaluations of SWB differ between age groups (A: plotted by type of diachronous rating; B: plotted by age group).

of present SWB. We were surprised to find that evaluations of past SWB were higher than that of the present, $F(2,1116)=167.43$, $p<.001, \eta^{2}=.13$, and evaluations of future SWB were lower than both present and past evaluations, $F(2,1116)=180.16, p<$ $.001, \eta^{2}=.14$ (see Figure 1$)$.

\section{Age Differences in Rank-Order Consistency Among Ratings of Past and Future SWB and Present SWB}

Before beginning the linear regression analysis procedures outlined below, we wanted to test whether the relations between diachronous ratings were indeed linear. Therefore, quadratic and cubic trends in the relations between past, present, and future evaluations of SWB were examined. Because only one of the six nonlinear trends tested was significant and it accounted for less than $1 \%$ of the variance, we focused on a linear approach.
Hierarchical regression analyses were conducted to determine the relations between present SWB and past or future SWB. First, simple models were computed regarding the relation between two diachronous ratings, respectively. Then, the robustness of these effects was examined by adding the identified control variables to the models. Subsequently, full models including age and age interactions were computed.

Simple models. A simple regression model to predict present SWB ratings in which ratings of past SWB were entered alone was used to compute the variance attributable to the past in predicting present SWB. Past SWB accounted for $13 \%$ of the variance in present SWB. A model in which future SWB was entered alone was used to compute the variance attributable to the future in predicting present SWB. Analyses showed that ratings of future SWB accounted for $42 \%$ of the variance in present SWB (see Models 1 and 3 in Table 2). 
Testing the robustness of diachronous relations. To alleviate concern that the effects found in the above analyses were due to personality, we repeated analyses with the addition of the personality variables. Thus, the five personality subscales and agency were entered on Step 1. On Step 2, the respective third diachronous rating was included as a control variable. When adding those control variables, the past uniquely still accounted for a significant $6 \%$ of the variance in predicting present SWB; that is, $54 \%$ of the original amount of predictive variance ( $7 \%$ of $13 \%$ ) was shared with the control variables. When using future SWB to predict present SWB, the addition of control variables decreased the predictive power of the future ratings to $29 \%$; that is, $31 \%$ of the original amount of predictive variance $(13 \%$ of $42 \%)$ was shared with the control variables.

Full models. The models including control variables were used to examine whether the relations between past and present ratings or future and present ratings of SWB were moderated by age. ${ }^{3}$ When adding the interaction term between age and past SWB after control variables, age, and past evaluations, a significant increase in explained variance $(1 \%)$ was observed. The same model, but using future ratings instead of past, was used to examine the age moderation of the relation between the future and the present. In this case, also $1 \%$ of predictive variance was added by the interaction term (see Table 3). Note that in the case of interaction terms after control for both of the main effects, it is not so much the effect size but the significance that is crucial (Cohen \& Cohen, 1983).

In follow-up analyses, we used the procedure suggested by Cohen and Cohen (1983). Thus, two extreme age groups were created following the rule of mean age plus or minus $1 S D(\leq 34$

Table 2

Hierarchical Regression Models for the Prediction of Present Subjective Well-Being (SWB) by Evaluations of Future SWB $(N=3,596)$

\begin{tabular}{|c|c|c|c|}
\hline Criterion $=$ present $\mathrm{SWB}$ & $R^{2}$ & $\Delta R^{2}$ & $F$ \\
\hline \multicolumn{4}{|l|}{ Model 1} \\
\hline Step 1: Past & .13 & - & 546.66 \\
\hline \multicolumn{4}{|l|}{ Model 2} \\
\hline \multicolumn{4}{|l|}{ Step 1: Extraversion } \\
\hline \multicolumn{4}{|l|}{ Openness } \\
\hline \multicolumn{4}{|l|}{ Neuroticism } \\
\hline \multicolumn{4}{|l|}{ Agreeableness } \\
\hline \multicolumn{4}{|l|}{ Conscientiousness } \\
\hline Agency & .18 & - & 130.59 \\
\hline Step 2: Future & .48 & .30 & 460.67 \\
\hline Step 3: Past & .54 & .06 & 516.57 \\
\hline \multicolumn{4}{|l|}{ Model 3} \\
\hline Step 1: Future & .42 & - & $2,580.25$ \\
\hline \multicolumn{4}{|l|}{ Model 4} \\
\hline \multicolumn{4}{|l|}{ Step 1: Extraversion } \\
\hline \multicolumn{4}{|l|}{ Openness } \\
\hline \multicolumn{4}{|l|}{ Agreeableness } \\
\hline \multicolumn{4}{|l|}{ Conscientiousness } \\
\hline \multicolumn{4}{|l|}{ Neuroticism } \\
\hline Agency & .18 & - & 130.59 \\
\hline Step 2: Past & .25 & .07 & 157.78 \\
\hline Step 3: Future & .54 & .29 & 516.57 \\
\hline
\end{tabular}

Note. The $F$ statistics reported test the significance of the incremental $\Delta R^{2}$ between steps in the model. For all $F \mathrm{~s}, p<.001$.
Table 3

Hierarchical Regression Models Identifying Age as a Moderator of Associations Among Diachronous Subjective Well-Being (SWB) Ratings $(N=3,596)$

\begin{tabular}{|c|c|c|c|}
\hline Criterion $=$ present $\mathrm{SWB}$ & $R^{2}$ & $\Delta R^{2}$ & $F$ \\
\hline \multicolumn{4}{|l|}{ Model 1} \\
\hline \multicolumn{4}{|l|}{ Step 1: } \\
\hline \multicolumn{4}{|l|}{ Neuroticism } \\
\hline \multicolumn{4}{|l|}{ Extraversion } \\
\hline \multicolumn{4}{|l|}{ Openness } \\
\hline \multicolumn{4}{|l|}{ Agreeableness } \\
\hline \multicolumn{4}{|l|}{ Conscientiousness } \\
\hline Agency & .18 & - & 130.59 \\
\hline Step 2: Future & .48 & .30 & 460.67 \\
\hline Step 3: Age & .56 & .08 & 555.76 \\
\hline Step 4: Past & .58 & .02 & 543.47 \\
\hline Step 5: Age $\times$ Past & .59 & .01 & 495.42 \\
\hline \multicolumn{4}{|l|}{ Model 2} \\
\hline \multicolumn{4}{|l|}{ Step 1: } \\
\hline \multicolumn{4}{|l|}{ Neuroticism } \\
\hline \multicolumn{4}{|l|}{ Extraversion } \\
\hline \multicolumn{4}{|l|}{ Openness } \\
\hline \multicolumn{4}{|l|}{ Agreeableness } \\
\hline \multicolumn{4}{|l|}{ Conscientiousness } \\
\hline Agency & .18 & - & 130.59 \\
\hline Step 2: Past & .25 & .07 & 167.78 \\
\hline Step 3: Age & .26 & .01 & 152.64 \\
\hline Step 4: Future & .58 & .32 & 543.47 \\
\hline Step 5: Age $\times$ Future & .59 & .01 & 490.03 \\
\hline
\end{tabular}

Note. The $F$ statistics reported test the significance of the incremental $\Delta R^{2}$ between steps in the model. For all $F \mathrm{~s}, p<.001$.

years, $n=769, M=29.68, S D=2.90 ; \geq 60$ years, $n=760$, $M=66.06, S D=4.36$ ). As Figure 2 (top panel) illustrates, the positive association (partial correlations [pr] using all control variables) between future and present well-being ratings was found to be stronger for the older, $\operatorname{pr}(760)=.75, p<.001$, than for the younger adults, $\operatorname{pr}(769)=.53, p<.001$. For illustrative purposes, we also plotted a group of middle-aged adults ( $\geq 40$ years and $\leq 50$ years, $n=884, M=45.54, S D=2.79$ ). The partial correlation for the middle group was $\operatorname{pr}(884)=.67, p<.001 .^{4}$

Using the same follow-up procedure for the interaction between the past and the present, the relation between past and present ratings was demonstrated to be stronger for the old than for the young adults. For those under 34 years, $\operatorname{pr}(769)=.11, p<.005$; for those older than 60 years, $\operatorname{pr}(760)=.40, p<.001$. Figure 2 (bottom panel) illustrates this finding. The partial correlation for the group of 40 to 50 -year-olds was $p r(884)=.26, p<.001 .^{5}$

\footnotetext{
${ }^{3}$ An initial model examined the effects of both age and gender. As gender added no predictive power to models explaining the present or the future, this variable was dropped in further analyses.

${ }^{4}$ The same pattern of results is found for all other domains except for welfare of others and marriage or partnership. Again, in those two cases the relation between future and present was also strong in young adulthood (for welfare of others, $r=.78$; for marriage or partnership, $r=.72$ ).

${ }^{5}$ The same pattern of results is found for all domains except welfare of others. In this domain the relation between past and present SWB was also strong for the young adults $(r=.61)$.
} 

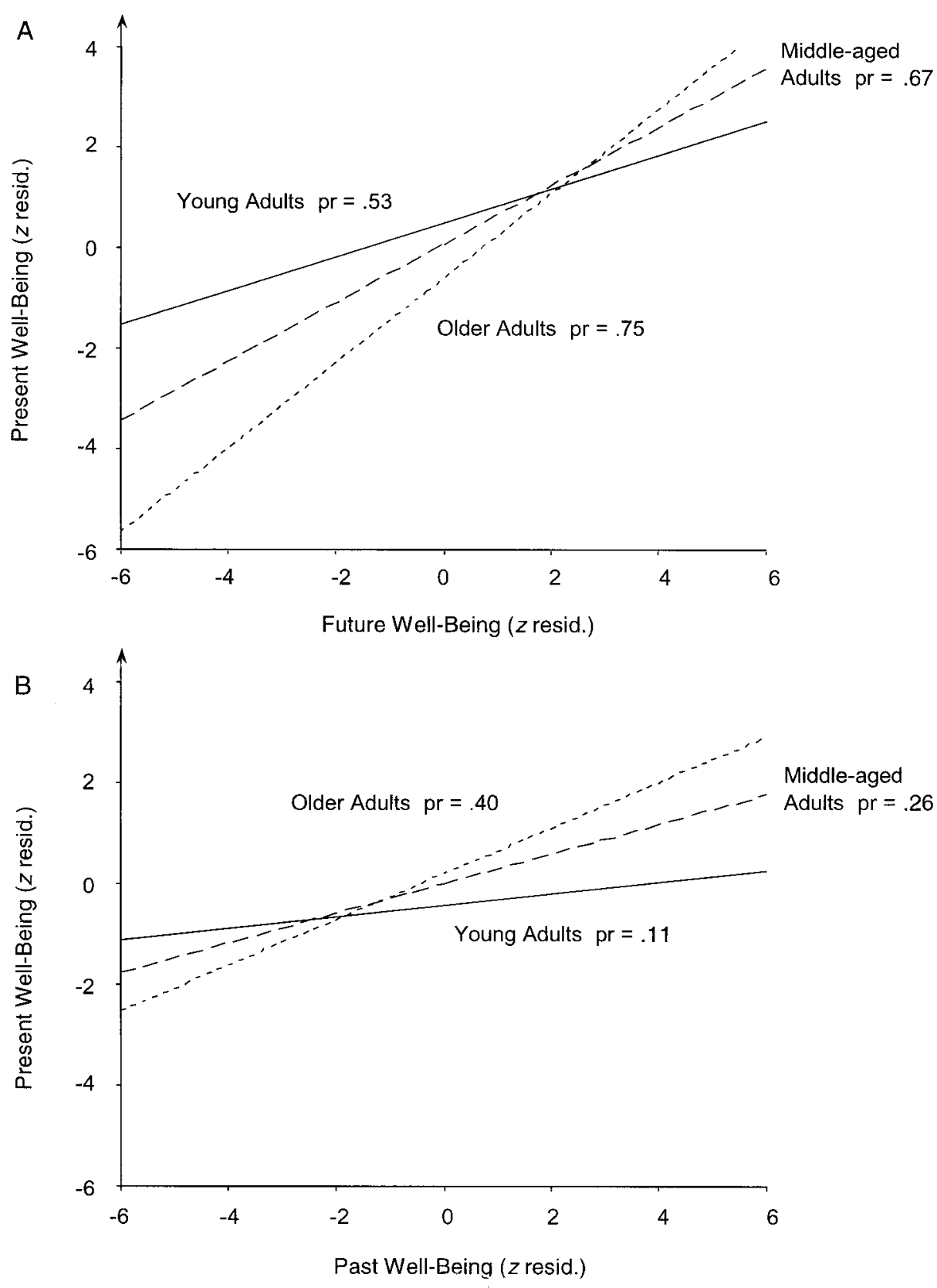

Figure 2. The relation of future to present (A) and past to present (B) SWB ratings in two age groups: Both the past and the future are more strongly related with the present in later adulthood. $\mathrm{pr}=$ partial correlation; resid. $=$ residual.

\section{Discussion}

In the study, we used a standard assessment procedure to examine mean-level and rank-order consistency among diachronous and present ratings of SWB across age. Some of our hypotheses were supported, and some surprising findings occurred.

\section{Overall Consistency Between Diachronous and Present Evaluations of SWB}

Mean-level consistency. As predicted, ratings of future SWB were significantly higher than present ratings, and past and present ratings of SWB did not differ. In a sample encompassing very heterogeneous life circumstances, nostalgia (Brickman et al., 1978) and enhancement effects (e.g., Wilson \& Ross, 2001) may average each other out, resulting in no visible overall differences. Indeed, a sample covering a heterogeneous age range of about 50 years (25-74 years) may encompass conditions of high loss as well as of gain. According to Brickman et al. (1978), life circumstances involving losses lead to what they called the nostalgia effect: that past SWB is rated higher than present SWB. In contrast, under conditions of growth, such as in young adulthood, for reasons of self-enhancement, the past is evaluated as worse than the present 
(cf. findings of Ryff, 1991; Wilson \& Ross, 2001). Consequently, by combining both conditions (age groups representing loss and growth) in one sample those two effects are averaged out. This interpretation is perfectly in line with the interaction between age and type of diachronous rating that qualified the main effect, and is discussed below.

The positive mean difference between evaluations of future and present SWB supports our hypothesis and replicates earlier findings (e.g., Brickman et al., 1978). Irrespective of life circumstances, future SWB is rated higher than that of the present. This finding is also consistent with the evidence that future ratings are more prone to self-deception than past ratings because they are less constrained by actual events (cf. Robinson \& Ryff, 1999). Again, discussion of age-specific findings will further elucidate this interpretation.

Rank-order consistency. As predicted, the rank-order consistency between evaluations of present and future SWB was higher than that between present and past SWB. Again, this is consistent with the findings by Robinson and Ryff (1999): A self-deceptive optimistic bias often guides projections into the future (but see below). This type of evaluative process seems less likely to lead to a change in the relative position of an individual in the group. Actual events, however, contribute at least to some degree to the evaluation of SWB in the past (Bluck, 2000). This makes it more likely that idiosyncratic events lead to change in rank orders, and thus lower interrelations are found. Note that this pattern holds true also when controlling for personality characteristics and the respective other diachronous rating.

Comparing results from the analysis of rank-order and meanlevel consistency demonstrates how it can be misleading to automatically infer small correlations given large mean-level differences and vice versa. Rather, both types of information truly complement each other, and each carries unique information.

\section{Age Groups Differ in Their Past, Present, and Future Mean Levels of SWB}

Young adulthood. Age-specific differences qualified the main effect of type of diachronous rating. As expected, in young adulthood future SWB was rated much higher and past SWB was rated much lower than present SWB. These results replicate earlier findings from studies of diachronous personality (Fleeson \& Heckhausen, 1997; Ryff, 1991; Wilson \& Ross, 2001).

This pattern of results is consistent with the three assumptions made in the beginning: On the basis of the findings by Schwarz and Strack (1999), we can infer that in young adulthood both past and future are part of different subjective time categories. Therefore, a contrast effect is observed that leads to the past being evaluated lower and the future being evaluated higher than the present. The valence of these contrasts is determined by the underlying motives of self-enhancement with regard to the past and self-improvement as well as the developmental motive of growth with regard to the future. In addition, we need to acknowledge that the growth story constructed by young adults also encompasses a self-assessment and/or a developmental belief component (see Figure 1, bottom panel). In young adulthood, we observe improvement in many domains of life as compared to 10 years ago, and there is at least some validity to the expectation of improving further in the 10 years to come (e.g., Baltes et al., 1998).
Middle-aged and older adults. In contrast, and against our expectations, older adults rated their past SWB higher and their future SWB lower than their present SWB. We had expected to find no differences between diachronous ratings of SWB and present SWB in old age. Thus, it seems that neither the motive of self-enhancement, in the sense of toning down losses, nor of self-improvement, in the sense of maintaining levels of functioning, are strong components in the judgment process of older adults. Rating past SWB higher than present SWB, which Brickman and others (1978) called a nostalgia effect, could actually also represent a realism or developmental belief component. Further, it is conceivable that remembering good old times ameliorates life in the present. This interpretation is in fact consistent with findings from studies of coping in old age that demonstrated that referring to past successes supports SWB in the present (e.g., Aldwin, Sutton, \& Lachman, 1996). Emphasizing the positive qualities of one's past also fits with the final developmental task of life, that is, integrating one's life as lived (Erikson, 1959).

Middle-aged adults showed the pattern that we had expected for old age, that is, no significant differences between ratings of past and present SWB were found (see Figure 1). Indeed, the losses experienced in middle adulthood are of a lesser and less generalized degree than in old age (Staudinger \& Bluck, 2001). On the basis of our hypotheses, we may infer that in midlife, selfenhancement and possibly developmental beliefs help to reconstruct those losses as stability; thus, a story of maintenance rather than decline emerges. Whereas in old age, the sense of loss may have become so pervasive that margins of illusions are surpassed (Baumeister, 1989), and consequently the relation between past and present is reconstructed quite realistically as a decline story.

The negative difference between future and present ratings of SWB in old age is a rather rare finding. Even though it is of smaller magnitude than the past-present difference (see Figure 1), it completes the decline story and is consistent with the interpretation that in old age rather realistic expectations about the SWB trajectory prevail (see also Ryff, 1991). It seems that rather than selfdeceptive optimistic biases, general developmental beliefs reign supreme when older adults evaluate their future SWB. In addition, overall smaller mean-level differences in old as compared with young adulthood indicate, as hypothesized, that in old age past and present as well as future and present indeed belong more to the same subjective time category than in young adulthood. We discuss exceptions from this rule below.

The middle-aged group demonstrated a pattern similar to the young adults (see Figure 1). In other words, in midlife the selfimprovement motive in the sense of future-orientation still seems to be an important component of the diachronous rating process. This is consistent with findings from research on the goal system and developmental regulation. Rather than achievement goals that characterize young and middle adulthood (e.g., Heckhausen, 2001), it is maintenance and avoidance goals that are typical of old age (e.g., Staudinger, Freund, Linden, \& Maas, 1999).

$A$ realism and/or developmental belief component. The conjecture that diachronous ratings also encompass a realism and/or developmental beliefs component (see also Fleeson \& Heckhausen, 1997), and not only optimistic or pessimistic selfdeceptive biases, receives some further support when exploring domain-specific findings. In domains that are characterized by early onset age-related declines, such as the health domain (e.g., 
Sehl \& Yates, 2001), evaluations of past and future SWB quite realistically reflect that decline even in young adulthood. In the case of health-related SWB, young adults also rated the past higher than the present and the present higher than the future. Thus, as speculated based on the realism and/or developmental beliefs component postulated above, young adults construct a decline story typical for their normative health trajectory into midlife. ${ }^{6}$ Similarly, in domains with an objective trajectory characterized by lifelong growth or at least stability, such as marriage or partnership, the diachronous pattern reported by old adults is a scaleddown version of the young adult pattern: Future SWB is rated higher than present SWB, and present SWB in turn is evaluated better than SWB in the past. ${ }^{7}$ And indeed, we know from research on marriage development across adulthood that with increasing age marriages that have survived are not on a decline but rather a stability or growth trajectory (e.g., Carstensen, Gottman, \& Levenson, 1995). Thus, given matching developmental experiences, older adults can indeed show the young adult diachronous pattern of a growth story and vice versa.

\section{Age Groups Differ in the Rank-Order Consistency of Diachronous Evaluations of Well-Being}

In this study, we wanted to complement the examination of mean-level consistency by analyzing age-related differences in rank order across diachronous ratings. On average, old people may evaluate the SWB of the past better than that of the present, and young people may rate their past SWB lower than that of the present. This pattern of results, however, does not tell us how consistently individuals in the respective age groups do so.

As predicted, rank-order consistency was much higher in old than in young adulthood. The middle-aged group fell between (see Figure 2). This implies that expectations for the future and evaluations of the past are less uniform in young as compared to later adulthood. In young adulthood, the past and the future are considered time categories that are separate from the present. Much change can be perceived to occur between the past and the future that modifies the relative position of individuals in the group. Whereas in old age, rank orders are more or less preserved across diachronous ratings. Midlife may mark the turning "point" in as much as time since birth and time until death strike a balance (Neugarten, 1979). Toward later adulthood and old age, we may experience more and more continuity among past, present, and future reflecting Erikson's last psychosocial crisis, integrating one's life as lived (Erikson, 1982). This final task involves making peace with the past and in doing so, being able to accept the future, that is, the end of life. In addition, research on time perspective has found that in later adulthood the "open present" (Nuttin, 1985) is the dominating temporal outlook on life. Taking this higher association between diachronous ratings in old as compared to young adulthood seriously may actually help to gain a deeper understanding of the subjective experience of individuals' movement through young adulthood, midlife, and into old age (see also Ryff, 1984).

\section{Support for a Diachronous View of Subjective Well-Being}

The results of the present study support the relevance of a diachronous view of life (Lewin, 1926; Ryff \& Baltes, 1976; Staudinger, 1999). Asking individuals to evaluate their life by taking different time perspectives appears to be a valid procedure. We found the same factor structure and satisfactory internal consistencies across diachronous ratings. Diachronous well-being ratings were shown to be meaningfully related to and yet not completely redundant with ratings of present SWB and with standard measures of personality. We need to acknowledge, however, that the disattenuated overall correlation between present and future SWB was almost perfect, suggesting that future ratings may carry very little unique information when compared with present ratings of SWB. This finding is qualified, however, by the age-specific differences in correlational patterns. Mean ratings of subjective well-being in the past, the present, and the future as well as their interrelations differed in predictable ways reflective of developmental life phases. Yet in most research to date, researchers only assess present SWB, ignoring these diachronous aspects. This may lead to imprecision in interpretations. For example, the very same present SWB rating can imply a perceived story of success or of failure. Considering diachronous patterns of SWB sees the present in relation to the remembered past and the anticipated future, and it may represent a more sensitive diagnostic means than ratings of SWB in the present only.

\section{Conclusion}

According to the present study, diachronous ratings of SWB not only reflect personality dispositions or self-serving biases but also realistic components and/or general beliefs about development. The three assumptions made in the beginning were successfully used to integrate extant theory and findings and make meaningful predictions. Developmental meanings of and limits to selfenhancement and self-improvement need to be acknowledged. It seems that with increasing age, self-enhancement less and less implies derogation of the past. Self-enhancement in the face of the final task of integrating one's life as lived seems to involve reconstructing a positive past (e.g., McAdams, 1990). With increasing age, self-improvement less and less implies growth or maintenance but actually may mean preparing for a difficult future. In addition, diachronous ratings not only follow a selfenhancement and self-improvement motive but also seem to be complemented by the motive of self-assessment, that is, a realistic and/or developmental beliefs component. Thus, theoretical conceptions of temporal self-evaluation need to provide for a realism and/or general developmental-belief component (see also Fleeson \& Heckhausen, 1997; Ryff, 1991).

Further research might address the age-graded adaptivity of mean-level as well as rank-order consistency or inconsistency among diachronous ratings of SWB. Being grounded in the present reflects the requirements and necessities of life at any point in the

\footnotetext{
${ }^{6}$ Young adults rated past SWB higher than present SWB, $F(1,1289)=$ $251.85, p>.001, \eta^{2}=.16, M=8.24, S D=1.74$. The difference between future and present evaluations of SWB in the domain of health reached, due to sample size, a significant $F$ value, but the zero effect size demonstrates that present and future ratings did not differ in a meaningful manner, $F(1$, 1289) $=5.85, p>.01, \eta^{2}=.00, M=7.50, S D=1.65$.

${ }^{7}$ Older adults rated their past SWB in the domain marriage or partnership lower than their present SWB, $F(1,733)=53.13, p>.001, \eta^{2}=.07$, $M=7.02, S D=2.76$, and their future SWB higher than present SWB, $F(1$, $733)=12.99, p>.001, \eta^{2}=.02, M=8.72, S D=1.83$.
} 
life span. Individuals' subjective well-being, however, extends from the present both into the past and into the future. Across the adult life span, the past and future not only change in their relative quantity but also in how they are reflected in our sense of diachronicity: Different trajectories of change are constructed, and the past and the future have different subjective significances for present well-being.

\section{References}

Albert, S. (1977). Temporal comparison theory. Psychological Review, 84, 485-503.

Aldwin, C. M., Sutton, K. J., \& Lachman, M. (1996). The development of coping resources in adulthood. Journal of Personality, 64, 837-871.

Arbuckle, J. L. (1999). AMOS (Version 4.01) [Computer software]. Chicago, IL: Smallwaters.

Baltes, P. B., Lindenberger, U., \& Staudinger, U. M. (1998). Life-span theory in developmental psychology. In R. M. Lerner (Ed.), Handbook of child psychology (Vol. 1, pp. 1029-1143). New York: Wiley.

Baltes, P. B., \& Mayer, K. U. (Eds.). (1999). The Berlin Aging Study: Aging from 70 to 100. New York: Cambridge University Press.

Baltes, P. B., Reese, H. W., \& Lipsitt, L. P. (1980). Life-span developmental psychology. Annual Review of Psychology, 31, 65-110.

Baumeister, R. F. (1989). The optimal margin of illusion. Journal of Social and Clinical Psychology, 8, 176-189.

Bluck, S. (2000). Autobiographical memories: Building blocks of life narratives. In G. Kenyon, B. deVries, \& P. Clark (Eds.), Narrative gerontology: Theory, research, and practice. New York: Springer.

Bluck, S., \& Levine, L. J. (1998). Reminiscence as autobiographical memory: A catalyst for reminiscence theory development. Ageing and Society, 18, 185-208.

Brandtstädter, J., \& Greve, W. (1994). The aging self: Stabilizing and protective processes. Developmental Review, 14, 52-80.

Brickman, P., Coates, D., \& Janoff-Bulman, R. (1978). Lottery winners and accident victims: Is happiness relative? Journal of Personality and Social Psychology, 36, 917-927.

Bühler, C. (1933). Der menschliche Lebenslauf als psychologisches Problem. [The human life course as a psychological problem]. Leipzig, Germany: Hirzel.

Campbell, A., Converse, P. E., \& Rodgers, W. L. (1976). The quality of American life: Perspectives, evaluations, and satisfaction. New York: Russell Sage Foundation.

Cantril, H. (1965). The pattern of human concerns. New Brunswick, NJ: Rutgers University Press.

Carstensen, L. L., Gottman, J. M., \& Levenson, R. W. (1995). Emotional behavior in long-term marriage. Psychology and Aging, 10, 140-149.

Cohen, J., \& Cohen, P. (1983). Applied multiple regression/correlation analysis for the behavioral sciences (2nd ed.). Hillsdale, NJ: Erlbaum.

Conway, M., \& Ross, M. (1984). Getting what you want by revising what you had. Journal of Personality and Social Psychology, 47, 738-748.

Costa, P. T., \& McCrae, R. R. (1984). Personality as a lifelong determinant of well-being. In C. Malatesta \& C. Izard (Eds.), Affective process in adult development and aging (pp. 87-101). Beverly Hills, CA: Sage.

Cross, S., \& Markus, H. (1991). Possible selves across the life span. Human Development, 34, 230-255.

Diener, E. (1994). Assessing subjective well-being: Progress and opportunities. Social Indicators Research, 31, 103-157.

Diener, E., Suh, E. M., Lucas, R. E., \& Smith, H. (1999). Subjective well-being: Three decades of progress. Psychological Bulletin, 125, 276-302.

Erikson, E. H. (1959). Identity and the life cycle. New York: International University Press.

Erikson, E. H. (1982). The life cycle completed. New York: Norton.

Fleeson, W., \& Baltes, P. B. (1998). Beyond present day personality assessment: An encouraging exploration of the measurement properties and predictive power of subjective lifetime personality. Journal of Research in Personality, 32, 411-430.

Fleeson, W., \& Heckhausen, J. (1997). More or less "me" in past, present, and future: Perceived lifetime personality during adulthood. Psychology and Aging, 12, 125-136.

Headey, B., \& Wearing, A. (1989). Personality, life events, and subjective well-being: Toward a dynamic equilibrium model. Journal of Personality and Social Psychology, 57, 731-739.

Heckhausen, J. (2001). Adaptation and resilience in midlife. In M. E. Lachman (Ed.), Handbook of midlife development (pp. 345-398). New York: Wiley.

Heckhausen, J., Dixon, R. A., \& Baltes, P. B. (1989). Gains and losses in development throughout adulthood as perceived by different adult age groups. Developmental Psychology, 25, 109-121.

Heidegger, M (1979). Sein und Zeit. [Being and time]. Tübingen, Germany: Niemeyer. (Original work published in 1927)

Hooker, K. (1992). Possible selves and perceived health in older adults and college students. Journal of Gerontology: Psychological Sciences, 47, P85-P95.

Hu, L., \& Bentler, P. M. (1995). Evaluating model fit. In R. H. Hoyle (Ed.), Structural equation modeling: Concepts, issues, and applications (pp. 76-99). Thousand Oaks, CA: Sage.

James, W. (1948). The principles of psychology. New York: World Book. (Original work published in 1890)

Jaspers, K. (1932). Die geistige Situation der Zeit [Mentality and time]. Berlin, Germany: de Gruyter.

Kahneman, D., Diener, E., \& Schwarz, N. (Eds.). (1999). Well-being: The foundations of hedonic psychology. New York: Russell Sage Foundation.

Karney, B., \& Coombs, R. H. (2000). Memory bias in long-term close relationships: Consistency or improvement? Personality and Social Psychology Bulletin, 26, 959-970.

Karniol, R., \& Ross, M. (1996). The motivational impact of temporal focus: Thinking about the future and the past. Annual Review of Psychology, 47, 593-620.

Levin, I., \& Zakay, D. (Eds.). (1989). Time and human cognition. Amsterdam: North Holland.

Levine, L. J. (1997). Reconstructing memory for emotions. Journal of Experimental Psychology: General, 126, 165-177.

Lewin, K. (1926). Untersuchungen zur Handlungs- und Affektpsychologie: I. Vorbemerkungen über die psychischen Kräfte und Energien und über die Struktur der Seele [Investigations regarding action and emotion psychology: I. Prolegomena about psychic power and energy and the structure of the soul]. Psychologische Forschung, 7, 294-329.

Lockhart, R. S. (1989). Consciousness and the function of remembered episodes. In H. L. Roediger \& F. I. M. Craik (Eds.), Varieties of memory and consciousness (pp. 423-430). Hillsdale, NJ: Erlbaum.

Markus, H., \& Nurius, P. (1986). Possible selves. American Psychologist, 41, 954-969.

Markus, H., \& Wurf, E. (1987). The dynamic self-concept: A social psychological perspective. Annual Review of Psychology, 38, 299-337.

McAdams, D. P. (1990). Unity and purpose in human lives: The emergence of identity as a life story. In A. I. Rabin, R. A. Zucker, R. A. Emmons, \& R. A. Frank (Eds.), Studying persons and lives (pp. 148-190). New York: Springer.

MIDMAC (1998). Midus. (Tech. Rep.). (Also available through http:// midmac.med.harvard.edu). Vero Beach, FL: Lifetrends.

Neisser, U. (1988). Five kinds of self-knowledge. Philosophical Psychology, 1, 35-59.

Neugarten, B. L. (1979). Time, age, and the life cycle. American Journal of Psychiatry, 136, 887-894.

Nuttin, J. (1985). Future time perspective and motivation (Louvain Psy- 
chology Series: Studia Psychologica). Leuven, Belgium: Leuven University Press.

Robinson, M. D., \& Ryff, C. D. (1999). The role of self-deception in perceptions of past, present, and future happiness. Personality and Social Psychology Bulletin, 25, 595-606.

Ross, M. (1989). Relation of implicit theories to construction of personal histories. Psychological Review, 96, 341-357.

Ross, M., \& Buehler, R. (2001). Identity through time: Constructing personal pasts and futures. In A. Tesser \& N. Schwarz (Eds.), Blackwell handbook in social psychology: Intrapersonal processes (pp. 518-544). Malden, MA: Blackwell.

Ross, M., \& Newby-Clark, I. R. (1998). Construing the past and future. Social Cognition, 16, 133-150.

Ryan, R. M., \& Deci, E. L. (2001). On happiness and human potentials: A review of research on hedonic and eudamonic well-being. Annual Review of Psychology, 52, 141-166.

Ryff, C. D. (1984). Personality development from the inside: The subjective experience of change in adulthood and aging. In P. B. Baltes \& O. G. Brim, Jr. (Eds.), Life-span development and behavior (Vol. 6, pp. 243-279). New York: Academic Press.

Ryff, C. D. (1991). Possible selves in adulthood and old age: A tale of shifting horizons. Psychology and Aging, 6, 286-295.

Ryff, C. D., \& Baltes, P. B. (1976). Values and transitions in adult development of women: The instrumentality-terminality sequence hypothesis. Developmental Psychology, 12, 567-568.

Ryff, C. D., \& Heincke, S. G. (1983). Subjective organization of personality in adulthood and aging. Journal of Personality and Social Psychology, 44, 807-816.

Schwarz, N., \& Strack, F. (1991). Evaluating one's life: A judgment model of subjective well-being. In F. Strack, M. Argyle, \& N. Schwarz (Eds.), Subjective well-being: An interdisciplinary perspective (pp. 27-47). Oxford, England: Pergamon Press.

Schwarz, N., \& Strack, F. (1999). Reports of subjective well-being: Judgmental processes and their methodological implications. In D. Kahneman, E. Diener, \& N. Schwarz (Eds.), Well-being: The foundations of hedonic psychology (pp. 51-84). New York: Russell Sage Foundation.

Sehl, M., \& Yates, F. E. (2001). Kinetics of human aging: I. Rates of senescence between ages 30 and 70 years in healthy people. Journals of Gerontology: Biological Sciences and Medical Sciences, 56, B198B208.

Smith, J. (1996). Planning about life: Toward a social-interactive perspective. In P. B. Baltes \& U. M. Staudinger (Eds.), Interactive minds: Life-span perspectives on the social foundation of cognition (pp. 242275). New York: Cambridge University Press.

Staudinger, U. M. (1999). Social cognition and a psychological approach to an art of life. In F. Blanchard-Fields \& T. Hess (Eds.), Social cognition, adult development and aging (pp. 343-375). New York: Academic Press.

Staudinger, U. M. (2000). Viele Gründe sprechen dagegen und trotzdem fühlen viele Menschen sich wohl: Das Paradox des subjektiven Wohlbefindens [The well-being paradox]. Psychologische Rundschau, 51, 185-197.

Staudinger, U. M., \& Bluck, S. (2001): A view on midlife development from life-span theory. In M. E. Lachman (Ed.), Handbook of midlife development (pp. 3-39). New York: Wiley.

Staudinger, U. M., Freund, A., Linden, M., \& Maas, I. (1999). Self, personality, and life regulation: Facets of psychological resilience in old age. In P. B. Baltes \& K. U. Mayer (Eds.), The Berlin Aging Study: Aging from 70 to 100 (pp. 302-328). New York: Cambridge University Press.

Staudinger, U. M., \& Pasupathi, M. (2000). Life-span perspectives on self, personality and social cognition. In T. Salthouse \& F. Craik (Eds.), Handbook of cognition and aging (pp. 633-688). Hillsdale, NJ: Erlbaum.

Suls, J., \& Mullen, B. (1982). From the cradle to the grave: Comparison and self-evaluation across the life-span. In J. Suls (Ed.), Psychological perspectives on the self (pp. 97-128). Hillsdale, NJ: Erlbaum.

Taylor, S. E., \& Brown, J. D. (1988). Illusion and well-being: A social psychological perspective on mental health. Psychological Bulletin, 103, 193-201.

Taylor, S. E., Neter, E., \& Wayment, H. A. (1995). Self-evaluation processes. Personality and Social Psychology Bulletin, 21, 1278-1287.

Trapnell, P. D., \& Wiggins, J. S. (1990). Extension of the interpersonal adjective scales to include the Big Five dimensions of personality. Journal of Personality and Social Psychology, 59, 781-790.

Tucker, L. R., \& Lewis, C. (1973). The reliability coefficient for maximum likelihood factor analysis. Psychometrika, 38, 1-10.

Wallach, M. A., \& Green, L. R. (1961). On age and the subjective speed of time. Journal of Gerontology, 16, 71-74.

Wilson, A. E., \& Ross, M. (2000). The frequency of temporal-self and social comparisons in people's personal appraisals. Journal of Personality and Social Psychology, 78, 928-942.

Wilson, A. E., \& Ross, M. (2001). From chump to champ: People's appraisals of their earlier and present selves. Journal of Personality and Social Psychology, 80, 572-584.

Woodruff, D. S., \& Birren, J. E. (1972): Age changes and cohort differences in personality. Developmental Psychology, 6, 252-259.

Received July 24, 2001

Revision received March 25, 2002

Accepted July 23, 2002

\section{Wanted: Your Old Issues!}

As APA continues its efforts to digitize journal issues for the PsycARTICLES database, we are finding that older issues are increasingly unavailable in our inventory. We are turning to our long-time subscribers for assistance. If you would like to donate any back issues toward this effort (preceding 1982), please get in touch with us at journals@apa.org and specify the journal titles, volumes, and issue numbers that you would like us to take off your hands. 